\title{
THE EFFECTIVENESS OF A TRAINING PROGRAMME UPON MAXIMUM AEROBIC POWER
}

\author{
QIAO JUXIANG*, WANG SHUYUN**, LI SHAOJUNG*** and LI ZHE† \\ *Associated Research Professor, Department of Sports Physiology, National Research Institute of Sport Science \\ ${ }^{*}$ * Research Assistant, Department of Sports Physiology, National Research Institute of Sports Science \\ *** "Senior Lecturer, Teaching and Research Section of Physical Education, Beijing Broadcasting College \\ tSenior Lecturer, Department of Physical Education, Beijing Teacher's University
}

\begin{abstract}
Forty-two trained and untrained young Chinese subjects of both sexes were employed for this study.

Maximal oxygen uptake and anaerobic threshold were measured with the Beckman Metabolic Measurement Cart (MMC) during incremental work test. Skinfold thickness was measured using a skinfold caliper. Body density was calculated with skinfold thickness according to the formula of Suzuki et al (1975). \% fat was calculated with the equation given by Brozek et al (1963).
\end{abstract}

$\%$ fat of trained subjects was significantly lower than untrained subjects in both sexes.

Maximal aerobic power of trained subjects was greater than untrained subjects in both sexes.

$\mathrm{VO}_{2}$ at "AT" in trained subjects was greater than untrained subjects in both sexes.

Anaerobic threshold might be a valid and useful physiological index for evaluation of physical fitness in various subjects.

Key Words: Maximal oxygen uptake, Anaerobic threshold, Body composition.

Maximal oxygen uptake anaerobic threshold and body compositon are valid physiological indices to evaluate physical fitness.

These indices are not only used to estimate one's physical performance, but also used to detect the effect of aerobic training and check the optimal training intensities in an aerobic training course.

Since Wasserman et al (1973) and Davis et al (1976) have studied anaerobic threshold with gas exchange method, the non-invasive anaerobic threshold as being more convenient method to discern anaerobic threshold was widely utilised in practice.

The purpose of this study is a preliminary investigation of maximal aerobic power non-invasive anaerobic threshold and body composition in trained and untrained subjects in both sexes.

\section{MATERIAL AND METHOD}

Forty-two young men and women subjects were studied; 12 male middle-long distance runners (trained group), 12 male college students (untrained group), 9 female well trained students (specialising in physical education) and 9 female non-PE students (untrained group) were employed for this study.
Body height and weight were measured using routine procedures.

Skinfold was measured with a skinfold caliper. Three sites of body were made on each subject: abdomen, arm and back.

Body density was calculated with skinfold thickness according to the formula of Suzuki et al (1975)." Calculation of body fat was made using the equation of Brozek et al (1963).

Incremental work test was performed by subject seated on the Monark ergometer for determination of maximal oxygen uptake and anaerobic threshold ("AT"). The pedalling rates were kept at $50 \mathrm{rpm}$. The initial work rate for female subjects was $25 \mathrm{~W}$ and $50 \mathrm{~W}$ for males. The work rate was increased by $25 \mathrm{~W}$ every two minutes to the limit of each subject's tolerance.

$\mathrm{O}_{2}$ and $\mathrm{CO}_{2}$ concentration in expired gas were obtained from the Beckman Metabolic Measurement Cart ( $M M C)$ by using manual methods during the incremental work test. Gas analysers for $\mathrm{O}_{2}, \mathrm{CO}_{2}$ were calibrated before each test.

*These sites are similar to those outlined by Astrand and Rodahl, 1977 - Editor. 
Gas exchange criteria parameters of anaerobic threshold were used according to the method of Wasserman et al (1973) and Davis et al (1976).

\section{RESULTS AND DISCUSSION}

The results are summarised in Tables I and II.

It was shown that the \% fat of trained groups was significantly lower than untrained groups in both sexes. Although there was no difference in lean body mass in male trained and untrained groups. If comparison of relative lean body mass (divided by body weight) in male subjects was made, the relative lean body mass for the trained group was $91.1 \%$, and $87.9 \%$ for the untrained group.

The lean body mass of the trained female subjects was heavier than the untrained. The relative lean body mass was $83.3 \%$ for the female untrained group and $78.7 \%$ for the untrained group.
The mean $\mathrm{VO}_{2}$ max either expressed per minute or per minute and kilogram of body weight and expressed per minute and kilogram of lean body mass in trained groups were greater than untrained groups in both sexes.

The mean $\mathrm{VO}_{2}$ at "AT" of trained groups was greater than untrained groups in both sexes.

Work rates at "AT" performed by trained groups was higher than untrained.

Total work time performed by trained subjects during the incremental exercise test was longer than untrained subjects in both sexes.

The data in this study indicated that improvement in body composition and the oxygen transport system was evident during physical training.

In view of physical fitness and physical performance great amounts of body fat can affect the performance of

TABLE I

\begin{tabular}{|c|c|c|c|c|c|c|c|c|c|}
\hline & & HT & WT & & & ATM & LBM & ATM/ & LBM / \\
\hline & Years & $\begin{array}{l}\mathrm{HT} \\
(\mathrm{cm})\end{array}$ & $\begin{array}{l}\text { WT } \\
\text { (kg) }\end{array}$ & DB & $\%$ FAT & $\begin{array}{l}\text { ATM } \\
(\mathrm{kg})\end{array}$ & $\begin{array}{l}\text { LBM } \\
(\mathrm{kg})\end{array}$ & $\begin{array}{l}\text { ATM/ } \\
\text { HT }\end{array}$ & $\begin{array}{l}\text { LBM/ } \\
\text { HT }\end{array}$ \\
\hline $\begin{array}{l}\text { Trained } \\
\text { group } \delta n=12\end{array}$ & 16.38 & 173.2 & 57.74 & $1.080^{* *}$ & $8.8 t$ & $5.08 t$ & 52.69 & $2.94^{* *}$ & 30.4 \\
\hline SD & 1.62 & 3.5 & 2.39 & 0.003 & 1.4 & 0.80 & 2.37 & 0.49 & 0.99 \\
\hline $\begin{array}{l}\text { Untrained } \\
\text { group ón=12 }\end{array}$ & 20.50 & 172.7 & 61.36 & 1.072 & 12.0 & 7.45 & 53.91 & 4.31 & 30.7 \\
\hline SD & 3.32 & 5.8 & 5.89 & 0.005 & 2.0 & 1.62 & 4.76 & 0.94 & 2.40 \\
\hline $\begin{array}{l}\text { Trained } \\
\text { group } \$ n=9\end{array}$ & 16.89 & 169.6 & $59.10 \dagger$ & 1.057 & $18.4^{* *}$ & 11.1 & $\begin{array}{r}49.06 \\
3\end{array}$ & 6.52 & $\begin{array}{c}28.9 \\
1.36\end{array}$ \\
\hline SD & 1.62 & 4.9 & 2.90 & 0.010 & 4.1 & 2.61 & 3.29 & 1.59 & 1.36 \\
\hline $\begin{array}{l}\text { Untrained } \\
\text { group }{ }_{n=9}\end{array}$ & 18.68 & 161.8 & 51.16 & 1.046 & 22.7 & 11.9 & 40.24 & 7.35 & 24.8 \\
\hline SD & 1.00 & 3.5 & 3.19 & 0.015 & 4.5 & 3.81 & 3.17 & 2.42 & 1.80 \\
\hline
\end{tabular}

TABLE ||

$$
\begin{aligned}
& \text { Trained } \delta \\
& n=12
\end{aligned}
$$

\begin{tabular}{|c|c|}
\hline $\mathrm{VO}_{2}$ & $\begin{array}{l}\text { I. } \min ^{-1} \\
\text { ml. } \mathrm{kg}^{-1} \mathrm{~min}^{-1} \\
\mathrm{ml} \mathrm{kg}^{-1} \mathrm{~min}^{-1} \text { (LBM) } \\
\text { I. } \mathrm{min}^{-1}\end{array}$ \\
\hline "AT" & $\% \mathrm{VO}_{2} \max$ \\
\hline
\end{tabular}

$$
\begin{aligned}
& 3.48 \pm 0.4 t \\
& 59.9 \pm 4.9 \\
& 66.1 \pm 5.5 t \\
& 2.24 \pm 0.24 t \\
& 66.0 \pm 12.6 \\
& 125 \\
& 1015 \\
& 125
\end{aligned}
$$$$
\text { work completed } k j
$$$$
\text { work limit body wt } \mathrm{kj} / \mathrm{kg}^{-1}
$$

$$
\begin{aligned}
& \text { Untrained } \delta \\
& n=12 \\
& 2.90 \pm 0.25 \\
& 47.5 \pm 4.2 \\
& 54.2 \pm 4.8 \\
& 1.94 \pm 0.1 \\
& 68.2 \pm 6.7 \\
& 100 \\
& 760 \\
& 76 \\
& 1.2
\end{aligned}
$$

Trained $?$ $n=9$

$$
\begin{aligned}
& 2.40 \pm 0.19 t \\
& 40.5 \pm 4.3 \\
& 49.0 \pm 6.1 \\
& 1.55 \pm 0.10 t \\
& 65.3 \pm 7.1 \\
& 100 \\
& 806 \\
& 81 \\
& 1.4
\end{aligned}
$$

Untrained 9 $n=9$

$$
\begin{gathered}
1.82 \pm 0.3 \\
35.7 \pm 4.5 \\
45.4 \pm 5.2 \\
1.26 \pm 0.1 \\
70.1 \pm 10.0 \\
75 \\
526 \\
39
\end{gathered}
$$$$
0.8
$$

$$
{ }^{*} P=0.05 \quad \text { * } P=0.01 \quad+P=0.001
$$


athletes. Less body fat stored and increase in specific gravity of body were recognised that there was a certain increase of the muscle and blood volume (Åstrand and Rodahl, 1977).

Maximal utilisation of $\% \mathrm{VO}_{2} \max$ without the increase of blood lactate was recognised as a very significant predictor of performance of endurance athletes (Costill, 1973; Kinderman et al, 1977).

Costill et al (1973) suggested that there was closer relationship between anaerobic threshold and running performance than maximal oxygen uptake.

It is easier accepted to estimate physical fitness and non-invasive methods to determine anaerobic threshold for older persons, children, sedentary subjects with poor physical fitness and patients with cardio-pulmonary disease who are unable to tolerate maximal work load for measurement of maximal oxygen uptake.

The test for determination of the anaerobic threshold is much lighter and the duration of this test is much shorter. There were also no accidents during the tests.

As Wasserman et al (1973) indicated, the easiest technique would be to measure VE during an incremental exercise test and to look for the point at which the VE-work rate curve becomes non-linear.

The results illustrate quite clearly the great contribution that this type of training can have on both sexes. Comparing trained with untrained men the latter reached only $56 \%$ in the completed work test. In the case of untrained women this similarly was $\mathbf{5 7 \%}$, which allows the generalisation that in these tests there is no sex difference and that untrained people can achieve only $55 \%$ of their potential work effectiveness. This is a justification for the need for correct and specific training programmes.

\section{CONCLUSIONS}

Forty-two trained and untrained subjects in both sexes were employed to investigate body composition, maximal aerobic power and anaerobic threshold. The conclusions were made as follows:

1. The \% fat of trained subjects calculating from skinfold was significantly lower than untrained groups in both sexes. But the relative lean body mass of trained group was greater than the untrained groups in both sexes.

2. Maximal aerobic power (I.min. ${ }^{-1} \mathrm{ml}_{\mathrm{kg}} \mathrm{k}^{-1} \mathrm{~min}^{-1}$, ml. $\mathrm{kg}^{-1} \mathrm{~min}^{-1}$ LBM) of trained groups was significantly greater than untrained groups in both sexes.

3. The $\mathrm{VO}_{2}$ at $\mathrm{AT}$ of trained groups was higher than the untrained groups in both sexes. Work rate at AT and total work time performed by the trained subjects were greater than the untrained groups in both sexes.

4. It is available to detect anaerobic threshold using the following parameters (VE, $\mathrm{VCO}_{2}, \mathrm{FECO}_{2}, \mathrm{FEO}_{2}$ and $\left.\mathrm{VE} / \mathrm{VO}_{2}\right)$. Anaerobic threshold is a valid and useful physiological index for the evaluation of physical fitness in various subjects.

\section{REFERENCES}

Åstrand, P.-O. and Rodahl, K., 1977 "Textbook of work physiology". 2nd Ed. New York. McGraw-Hill.

Brozek, J., Grande, F., Andreson, J. T. and Keys, A., 1963 “Densitometric analysis of body composition: Review of some quantitative assumptions". Ann.N.Y.Acad.Sci. 110: 113-140.

Costill, D. L., Thomson, H. and Roberts, E., 1973 "Fractional utilisation of the aerobic capacity during distance running". Med.Sci.Sports 5: 248-252.

Davis, J. A., Vodak, P., Wilmore, J. H., Vodak, J. and Kurts, P., 1976 "Anaerobic threshold and maximal aerobic power for three modes of exercise". J.Appl.Physiol. 41: 544-550.

Kinderman, W., Simon, G. and Keul, J., 1979 "The significance of the aerobic-anaerobic transition for determination of work load intensities during endurance training". Eur.J.Appl.Physiol. 42: 25-54.

Wasserman, K., Whipp, B. J., Koyal, S. M. and Bearer, W. L., 1973 “Anaerobic threshold and gas exchange during exercise". J.Appl.Physiol. 35: 236-243. 